\title{
The Morphological Basis of Dementia in Parkinson's Disease
}

\author{
M.J. Ball
}

\begin{abstract}
The literature pertinent to the pathological anatomy subserving dementia in Parkinsonian patients is reviewed. Mechanisms discussed include cerebral cortical atrophy; hydrocephalus; Lewy body inclusions; neocortical lesions of the Alzheimer type; depletion of cholinergic, dopaminergic or noradrenergic transmitter systems; 'subcortical' dementia; and neuronal depopulation of the basal forebrain.
\end{abstract}

New autopsy data are presented to confirm that, contrary to published reports, most patients with parkinsonism who exhibit dementia do not have concomitant Alzheimer's disease, and that some different pathogenetic mechanism must be sought to account for this increasingly common cause of cognitive decline in the sufferers of Parkinson's disease.

RÉSUMÉ: Nous revisons la littérature sur l'anatomie pathologique de la démence chez les patients Parkinsoniens. Les mécanismes discutés incluent l'atrophie corticale cérébrale; l'hydrocéphalie; les inclusions en corps de Lewy; les lésions néocorticales du type Alzheimer; les déplétions des systèmes cholinergiques, dopaminergiques ou noradrénergiques; la démence souscorticale; et la dépopulation neuronale du tronc.

Nous présentons de nouvelles données autopsiques montrant contrairement aux rapports publiés, que la plupart des patients avec Parkinsonisme et démence n'ont pas une maladie d'Alzheimer associée. Il faut donc rechercher d'autres mécanismes pathogéniques pour expliquer cette cause de plus en plus fréquente du déclin cognitif chez les Parkinsoniens.

Can. J. Neurol. Sci. 1984; 11:180-184

While much is already understood about the pathological anatomy underlying the disorders of movement in patients with parkinsonism, the structural basis for the frequently observed impairment of cognitive function in Parkinson's disease remains to be elucidated. The first part of this presentation reviews the information available to date in the literature, and in the second portion some new data relevant to this question are presented from the Neuropathology Research Laboratory at the University Hospital, University of Western Ontario.

\section{Clinical Observations}

In his essay on "the shaking palsy", Parkinson considered the intellect not to be involved in the patients he originally described (Parkinson, 1938), but he did make reference to certain mental symptoms which these people exhibited, such as "depression" and "a terminal delirium" (Mayeux and Stern, 1983). That the cognitive dysfunction accompanying parkinsonism represents a major health problem, probably second only to senile dementia of the Alzheimer type, can be deduced from estimates of the frequency of dementia in Parkinson's disease, which vary from $30 \%$ (Buchwald et al., 1975) to as high as $93 \%$ of all cases (Pirozzolo et al., 1982). Since the prevalence of Parkinson's disease (one of the commonest neurological disorders) steadily increases after age 40 , there may be between 150,000 and 390,000 sufferers with this condition in the United States (Kessler, 1978); and if only $30 \%$ have some intellectual impairment, up to 117,000 may be showing dementia, or in Canada a roughly equivalent number of about 12,000 Parkinsonians with dementia.
The degree of this intellectual decline is not infrequently considerable; Martin et al. (1973) found that more than one-fifth of their dementing parkinsonian subjects had a moderate to severe degree of intellectual dysfunction.

The clinical criteria to diagnose dementia occurring in Parkinson's disease basically follow those described in the third edition of the Diagnostic and Statistical Manual of Mental Disorders (DSM III, 1980), and are shown in Table 1. Expressed more simply, Benson (1975) points out that dementia involves deterioration of some or all of the following - cognition, memory, calculation, language, perception, and emotionality. In characterizing the nature of the intellectual decline, certain mental

Table 1: Diagnostic criteria for dementia

1. Loss of intellect sufficient to impair social or occupational function

2. Memory impairment

3. One of the following:

a. impaired abstraction

b. impaired judgment

c. aphasia

d. apraxia

e. agnosia

f. constructional difficulty

g. personality change

4. Alert state of consciousness

From the Departments of Pathology. Clinical Neurological Sciences and Psychiatry, University of Western Ontario, London. Ontario.




activites such as visuospatial or perceptual motor function are very often disturbed, whereas others such as language may be relatively spared. As shown in Table 2, perceptual deficits may include poor performance on the Digit Symbol Subtest from the Wechsler Adult Intelligence Scale, inability to recognize complex visual stimuli, defective map or route walking, and poor judgment of the visual vertical. Such deficits have been observed in a recent study of elderly parkinsonians living in the province of Ontario (Moss, 1982).

\begin{tabular}{|c|c|c|c|}
\hline Investigator & Year & No. pts. & Deficit \\
\hline DeLancy-Horne & 1971 & 11 & $\begin{array}{l}\text { Delayed recognition of } \\
\text { complex visual forms }\end{array}$ \\
\hline Bowen et al. & 1972 & 47 & $\begin{array}{l}\text { Defective route or map } \\
\text { walking }\end{array}$ \\
\hline Lorranger et al. & 1972 & 63 & $\begin{array}{l}\text { Perceptual motor tasks } \\
\text { (WAIS) }\end{array}$ \\
\hline Danta and Hilton & 1975 & 65 & $\begin{array}{l}\text { Judgment of visual } \\
\text { vertical-horizontal }\end{array}$ \\
\hline $\begin{array}{l}\text { Yahr and Proctor- } \\
\text { Brown }\end{array}$ & 1975 & 86 & Visual reproduction \\
\hline Flowers & 1978 & 15 & Tracking of wave forms \\
\hline Flowers & 1978 & 10 & $\begin{array}{l}\text { Predictive hand move- } \\
\text { ments for tracing }\end{array}$ \\
\hline Mortimer et al. & 1982 & 60 & Visuospatial perception \\
\hline Stern et al. & 1982 & 16 & $\begin{array}{l}\text { Tracing of lines and } \\
\text { complex forms }\end{array}$ \\
\hline $\begin{array}{l}\text { Tomaino et al. } \\
\text { (unpublished data) }\end{array}$ & 1982 & 22 & Haptic maze perception \\
\hline
\end{tabular}

from Mayeux and Stern, 1983

Compared with other diseases in which dementia occurs, Parkinson's is distinct because of the lack of significant language impairment. Mayeux and coworkers (Mayeux et al., 1981) measured the severity of functional disability on clinical rating scales in Parkinson's, Alzheimer's disease, and Huntington's disease. Although age and educational status were similar, the demented Parkinsonian patients were less impaired in their language, calculations, and memory tasks than the patients with senile dementia of the Alzheimer type. Those parkinsonians with mild disability only performed similar to a group of elderly, healthy controls; and the severely disabled patients with Parkinson's disease performed no worse than those patients with Alzheimer's having only mild disability.

Numerous investigators have examined the parallel relationship between the severity of the clinical features of parkinsonism and the extent of such patients' intellectual impairment. As shown in Table 3, such factors as the age of the subject, the degree of motor disability, and the degree of bradykinesia have all been correlated positively to a significant extent with the degree of intellectual change (Celesia and Wanamaker, 1972; Garron et al., 1972; Marttila and Rinne, 1976; Mortimer et al., 1982). Using a 57-point modified version of the Mini-Mental Status Examination (Folstein et al., 1975), Mayeux and Stern have shown a striking correlation between the severity of the parkinsonism and the degree of intellectual impairment (Mayeux and Stern, 1983). That correlation coefficient suggests that as the severity of the symptoms of Parkinson's increase, the degree of intellectual impairment also gets greater. The specific weight
Table 3: Relationship between intellectual impairment and Parkinson's Disease

\begin{tabular}{|c|c|c|c|}
\hline Investigator & Year & No. pts. & $\begin{array}{l}\text { Factors related to } \\
\text { intellectual dysfunction }\end{array}$ \\
\hline Garron et al. & 1972 & 47 & $\begin{array}{l}\text { Age, degree of disability. } \\
\text { particularly akinesia }\end{array}$ \\
\hline Loranger et al. & 1972 & 63 & $\begin{array}{l}\text { Severity of clinical symp- } \\
\text { toms and functional } \\
\text { disability }\end{array}$ \\
\hline $\begin{array}{l}\text { Celesia and } \\
\text { Wanamaker }\end{array}$ & 1972 & 153 & $\begin{array}{l}\text { Age, duration of illness, } \\
\text { degree of motor disa- } \\
\text { bility }\end{array}$ \\
\hline Martilla and Rinne & 1976 & 444 & Age, hypokinesia, rigidity \\
\hline Lieberman et al. & 1979 & 520 & $\begin{array}{l}\text { Late age of onset, severity } \\
\text { of disease }\end{array}$ \\
\hline $\begin{array}{l}\text { Matthews and } \\
\text { Haaland }\end{array}$ & 1979 & 42 & Duration of illness \\
\hline Mayeux et al. & 1981 & 55 & Depression \\
\hline Mortimer et al. & 1982 & 60 & Bradykinesia \\
\hline
\end{tabular}

from Mayeux and Stern, 1983

for a variety of quantitative measures of the tremor, rigidity, bradykinesia and other symptoms could be calculated from the appropriate items in this parkinsonism disease evaluation score. By using a stepwise multiple regression analysis, Mayeux and Stern were able to determine the strength of the relationships with the specific components of the mini-mental subtests, to evaluate possible predictive power for these numerous variables. Five characteristics were found particularly to be associated with intellectual impairment (Table 4): increasing age, education, depression, bradykinesia, and rigidity. Since the strongest predictors of the overall performance on the mini-mental state evaluation were bradykinesia and rigidity, this investigation drew a distinct parallel between clinical indications of dysfunction of the basal ganglia and the intellectual impairment.

\begin{tabular}{lcr}
\hline Table 4: Profile of Parkinsonian subjects $(\mathbf{N}=\mathbf{5 5})$ & \\
\hline \hline Age & 67.5 & $($ S.D. \pm 8.7$)$ \\
Education & 12.5 & $(4.6)$ \\
PDE Score & & \\
$\quad$ Total & 29.0 & $(17.8)$ \\
Tremor & 2.3 & $(3.2)$ \\
Rigidity & 5.2 & $(3.8)$ \\
Bradykinesia & 1.2 & $(1.0)$ \\
\% ADL & 67.0 & $(23.3)$ \\
Duration of illness & 9.0 & $(9.7)$ \\
Levodopa (g/day) & 2.77 & $(1.9)$ \\
\end{tabular}

PDE, Parkinson's Disease evaluation

ADL, activities of daily living

\section{Pathological Observations}

With these publications as background, let us turn now to a consideration of questions arising from the search for a neuropathological basis for the dementia seen in people with Parkinson's disease. Is cerebral atrophy important? Pneumoencephalography has certainly revealed cortical shrinkage in more than half of parkinsonian patients referred for thalamic surgery 
(Selby, 1968). In such a group, however, no association was observed between the presence of the atrophy and the mental function. The amount of atrophy in the parkinsonian group was greater than in age-matched controls, but there was no description of cognitive impairment. Yahr and his coworkers found dementia to be frequently associated with the "atypical" type of Parkinsonians, those manifesting a rapid or unusual evolution of their disease. More than two-thirds of these kinds of patients did have ventricular enlargement on CAT scans of their brain (Sroka et al., 1981). This sort of study raises a second question - whether ventricular dilatation is related to parkinsonian dementia.

One of the earliest major studies of the neuropathology was that by Alvord, Forno and colleagues (Alvord et al., 1975), who examined the brains of more than 500 patients with Parkinson's disease. Two distinct degenerative patterns were described. In the first, the so-called "Lewy body" type or what we now refer to as idiopathic Parkinson's disease, the severity of the parkinsonian symptoms correlated well with the nerve cell loss in the substantia nigra, which like the locus ceruleus, displays large numbers of neurons containing these Lewy body inclusions. The degree of dementia, however, correlated best with the presence of neurofibrillary tangles in neocortical nerve cells. By contrast, in the second variety, the so-called "Alzheimer tangle" type of Parkinson's disease - or what we now believe is post-encephalitic parkinsonism, only a weak relationship could be seen between neuronal loss in substantia nigra and the parkinsonian features, although again the degree of neocortical neuronal degeneration did correlate with the dementia. This sort of retrospective investigation suggests that the more frequent neocortical pathology in parkinsonians accounted for the proportionately higher number who had dementia than did age-matched controls. At the 1983 annual meeting of the Canadian Association of Neuropathologists, Clark and Lehmann (1983) discussed two female patients with progressive dementia clinically thought to be of the Alzheimer variety, a fifty year old and a seventy-three year old woman. At autopsy, while only small to modest numbers of tangles and plaques could be found in the neocortex of these brains, Lewy bodies were extremely numerous throughout the neuromelanin-pigmented nuclei of the brainstem, but also widespread throughout neocortical nerve cells in frontal, temporal, and parietal regions. Neither of these patients showed clinical parkinsonism, but in that the choline acetyltransferase activity from five different parts of their neocortex was extremely low, Clark suggests that this so-called "dementia with widespread Lewy bodies" may represent one end of a spectrum which includes classical Parkinson's and Parkinson's with dementia (Clark and Lehmann, 1983). Of similar interest is a very recent report from the Albert Einstein College of Medicine, in an immunohistochemical study of five people with idiopathic parkinsonism, one of whom also showed dementia (Goldman et al., 1983). These patients' Lewy body inclusions show positive reactions against normal neurofilament antigen. Although the ultrastructural configuration of the filamentous organization within a Lewy body is not helical, like the paired helical filaments in the neurofibrillary tangle, single paired helical filaments have been seen at the edge of Lewy bodies, or inside Lewy bodies within a nerve cell process, and occasionally one neuron contains both a Lewy body and a neurofibrillary tangle. It may therefore be that some marked disorganization of neurofilament protein is a histological feature of Parkinson's disease.
This brings us to a consideration of whether "Alzheimerization" of the central nervous system in Parkinson's disease can explain the dementing symptomatology. The possible role of the neurofibrillary tangle of Alzheimer in parkinsonian dementia was most notably championed by Gordon Mathieson, from the Montreal Neurological Institute, first in a letter to the Lancet in 1978, and subsequently in a full article with Hakim in Neurology, 1979 (Hakim and Mathieson, 1978; 1979). The histological features in 34 consecutive cases which at autopsy met the pathological criteria for Parkinson's disease were compared with 34 age and sex-matched control brains. Only $6 \%$ of the controls gave any retrospective evidence for mental impairment, whereas $56 \%$ of the Parkinsonians showed clinical features of mental disturbance, varying from "disorientation and mild confusion" to severe dementia. Using a rather crude scoring system for neuritic plaques, neurofibrillary tangles, granulovacuolar degeneration and neuronal loss, these authors graded such histological features on a scale of 0 to +3 , but supplied no evidence of reproducibility or of inter-observer agreement for this scoring schema. What is more, while the histological evaluation certainly showed that the chance of finding such Alzheimer lesions was considerably higher in brains of parkinsonians than in controls, there was no statement whatsoever about whether these lesions were more severe in those parkinsonians who showed dementia as well! The table provided with that manuscript can be readily analyzed, however; and for example, Student's t test shows no significant difference between the mean number of neurofibrillary tangles in 19 subjects with dementia (1.63) when compared with the 15 others without dementia (1.33; $\mathrm{p}>0.1$, two-tailed $\mathrm{t})$; Table 5 .

Table 5: Neurofibrillary Tangles in Parkinson's Disease

$\begin{array}{ll}\begin{array}{c}\text { Not demented: } \\ (\mathrm{n}=15)\end{array} & 1.33( \pm 0.98) \\ \begin{array}{c}\text { Demented: } \\ (\mathrm{n}=19)\end{array} & 1.63( \pm 0.96)\end{array}$

(extrapolated from Hakim \& Mathieson, 1979)

This might be an ideal time to review for a moment our notion of whether plaques and tangles readily explain dementia even in classical Alzheimer's disease. A very strong correlation between the clinical dementia score and the number of neuritic or senile plaques has been widely quoted ever since the 1960's, based on a study by the group at Newcastle-upon-Tyne (Blessed et al., 1968). Critical evaluation of Tomlinson's paper, however, shows that the value of $\mathbf{0 . 7}$ for the correlation coefficient, " $r$ ", is almost certainly spuriously high, due to the lack of homogeneity for the presence of dementia in the subjects upon which the calculation was based. Such a high " $r$ " value can easily be obtained if one lumps together two different populations, generally located at either end of the $X$ axis. This concept has been brought into even further question by workers from Oxford, who have recently found that the strength of the correlation between the severity of dementia and the number of neuritic plaques is weak and inconstant, although that with neurofibrillary tangles is somewhat more impressive (Wilcock and Esiri, 1982; Wilcock et al., 1982).

I have recently had the opportunity to quantify the degree of formation of neurofibrillary tangles in some parkinsonian material 
available in the Neuropathology Research Laboratory at University Hospital, London, Ontario. Earlier work in my laboratory had indicated that within the hippocampal formation, while there is a slight increase in the degree of neurofibrillary degeneration with normal aging, this type of lesion is anywhere from 6 to 40 times more severe in patients dying with Alzheimer's disease (Ball, 1976; 1977). These earlier studies surveyed 794,510 microscopic fields in 19 normal controls and 8 patients with Alzheimer's disease. The number of nucleolated, pyramidal neurons containing tangles per cubic millimeter of hippocampal cortex, which we have called the "Adjusted Tangle Index", averaged 4.35 in the mentally preserved, age-matched individuals, but was 90.29 in the patients with Alzheimer's disease and occasionally ranged beyond 150 or 200 (Table 6). The Adjusted Tangle Index has now been calculated as well in 7 patients with a clinical diagnosis of Parkinson's disease. Fortuitously, the 5 of these 7 who showed dementia as well as their parkinsonism turned out to be age-matched with both the 19 normals and the 8 Alzheimer cases. 66,056 additional microscopic fields were screened using our semi-automated, sampling stage microscope.

Table 6: Adjusted Tangle Index in Controls and in Alzheimer's Disease or Parkinson's Disease with Dementia

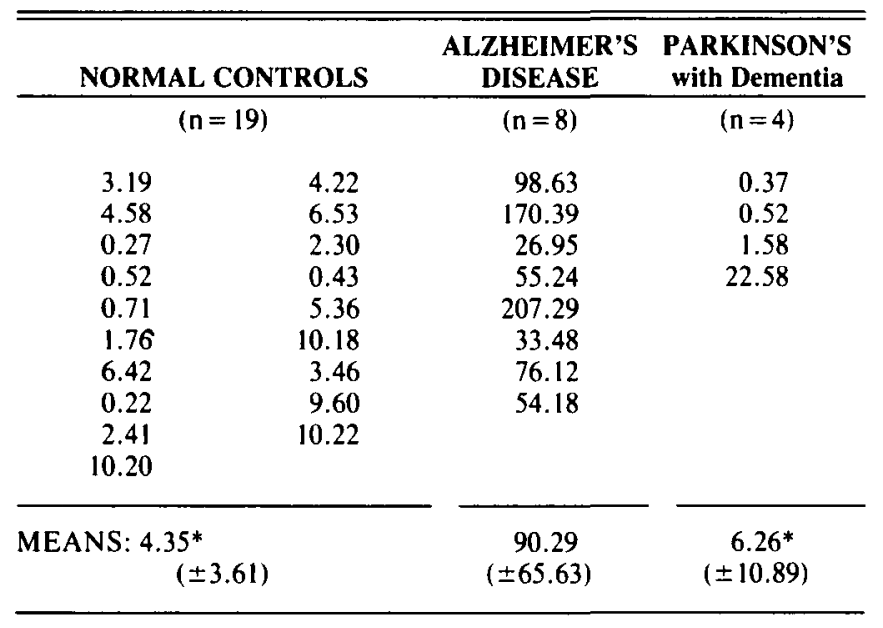

$$
\begin{gathered}
\text { *No sign. diff. } \\
(p>0.1,2 \text {-tailed } t)
\end{gathered}
$$

In the first four parkinsonians who also manifested some degree of dementia, the mean Adjusted Tangle Index, at 6.26, did not differ significantly either from two other parkinsonians without dementia (mean, 6.27) or from our earlier, normal controls (Table 6). This is especially interesting, in that two of these four demented Parkinson's patients had both clinical and neuropathological evidence for the postencephalitic variety, in which neurofibrillary tangles should if anything have been even more common. Our finding is in agreement with the observation of Mann and Yates (1983) that the number of tangles and plaques whether in 3 demented patients with idiopathic parkinsonism or 5 parkinsonians without dementia was no greater than in 20 age-matched controls, and by no means approached the elevated density seen in Alzheimer's cases.

A fifth parkinsonian, a man of 85 years of age, had been clinically diagnosed as also suffering from senile dementia of the Alzheimer type, which was confirmed at autopsy. His mean hippocampal tangle-count, at 82.05 , did fall within the Alzheimer range, but such a concomitance of both SDAT and idiopathic parkinsonism would appear from this small sample to be the exception, rather than the rule. In their letter to the Lancet earlier this month, Perry et al. likewise found that only one of seven demented cases dying with idiopathic Parkinson's disease showed pathological evidence of coexistent Alzheimer's Disease (Perry et al., 1983b).

Because of the enormous interest in the apparent deficiency of the cholinergic neurotransmitter system observed in Alzheimer's disease, the biochemical marker for acetylcholine, the activity of the synthetic enzyme choline acetyltransferase has also been recently surveyed in some demented patients with Parkinson's disease (Ruberg et al., 1982). The ChAT activity was found to be reduced, although the characteristics of these subjects' dementia were not described. Clark and Lehmann (1983) have likewise noted that Alzheimer-type histological changes may be minor in importance, in the presence of a severe hypocholinergia in a dementing patient's brain. The ChAT activity in all seven demented Parkinsonians reported by the Perrys was also severely reduced, despite the absence of Alzheimer histopathology in six of those seven brains (Perry et al., 1983b). This neurochemical explanation, as well as the possibility of loss of dopamine in neocortical neurons within projection areas receiving inputs from the mesencephalon (JavoyAgid et al., 1981; Lees and Smith, 1983) is more thoroughly discussed by Hornykiewicz (this volume). Because the basal ganglia do participate in some intellectual activities, and since there is a remarkable parallelism between intellectual dysfunction and the severity of the extrapyramidal manifestations, some authors such as Boller (1980) have suggested that some of the neuropsychological changes in Parkinson's disease may be subcortical in nature. Whether these would be thalamic, or striatal, is unclear.

A final theory concerns the basal forebrain nuclei. The suggestion that these magnocellular neurons, located particularly within the nucleus basalis of Meynert in the substantia innominata, could underlie the dementia of Alzheimer's disease was first published in 1982 by the group from Baltimore (Whitehouse et al., 1982a). A more extensive examination of five normals and five patients with Alzheimer's disease was published shortly thereafter (Whitehouse et al., 1982b). Since studies from lower mammals indicate more than $70 \%$ of the cholinergic afferentation to the neocortex originates from the basal forebrain nuclei, it is very tempting to hypothesize that these regions suffer from extensive neuronal destruction in Alzheimers' disease. To date, however, the published evidence for this concept in human material remains inconclusive. The five controls in the paper by Whitehouse, said to be "of comparable age", were significantly younger on average by some eight years, so that the apparently extensive reduction in population of Meynert's neurons may well have been at least in part an aging phenomenon. Several British workers have also quantified this population in the nucleus basalis, but find the neuronal loss in SDAT to be much less impressive (Perry et al., 1983; Wilcock et al., 1983; Candy et al., 1983). Moreover, until the precise geographic boundaries of these forebrain nuclei have been carefully mapped in the human CNS, and until reproducible morphometric techniques are carried out on serial sections throughout the entire region, one should probably preserve a healthy skepticism about the similar claims that selective cell loss in such regions can also explain the dementia either of idiopathic Parkinson's disease 
(Whitehouse et al., 1983) or of the Parkinsonism-dementia complex of Guam (Nakano and Hirano, 1983).

In spite of all these hurdles, of course, the neuropathological as well as the biochemical basis for the dementia in Parkinson's disease surely merits far more scientific attention, and holds an enormous promise for eventual therapeutic manipulation, and even for a deeper comprehension of basic pathogenetic mechanisms. Well documented clinical cases, which can be followed longitudinally until postmortem examination, offer a truly unique opportunity to unravel this riddle.

\section{ACKNOWLEDGEMENTS}

Supported in part by grants from the National Institutes of Health (AGNS03047), Medical Research Council of Canada (PG21), and the Ontario Mental Health Foundation (858). Ms. Nancy Joslin typed the manuscript. Mrs. JoAnn MacGregor supervised the technical work.

\section{REFERENCES}

Alvord EC, Forno LS, Kusske JA, Kauffman RJ, Rhodes JS, Goetowski CR (1975) "The Pathology of Parkinsonism: A Comparison of Degenerations in Cerebral Cortex and Brainstem", Advances in Neurology 5: 175-193.

Ball MJ (1976) "Neurofibrillary Tangles and the Pathogenesis of Dementia - A Quantitative Study", Neuropathology and Applied Neurobiology 2: $395-410$

Ball MJ (1977) "Neuronal Loss, Neurofibrillary Tangles and Granulovacuolar Degeneration in the Hippocampus with Aging and Dementia", Acta Neuropathologica 37: 111-118.

Benson D Frank (1975) "The Hydrocephalic Dementias", in: "Psychiatric Aspects of Neurologic Disease', edited by D.F. Benson and D. Blumer, Grune and Stratton, New York, Pages 83-98.

Blessed G, Tomlinson BE, Roth M (1968) "The association between quantitative measures of dementia and of senile changes in the cerebral grey matter of elderly subjects", British Journal of Psychiatry 114: 797-811.

Boller F (1980) "Mental Status of Patients with Parkinson Disease", Journal of Clinical Neuropsychology 2: 157-172.

Buchwald NA, Hull CD, Levine MS, Villablanca J (1975) "The Basal Ganglia and the Regulation of Response and Cognitive Sets", in: 'Growth and Development of the Brain', edited by M.A.B. Brazier, Raven Press, New York, Pages 171-189.

Candy JM, Perry RH, Perry EK, Irving D, Blessed G, Fairbairn AF, Tomlinson BE (1983) "Pathological Changes in the Nucleus of Meynert in Alzheimer's and Parkinson's Disease", Journal of the Neurological Sciences 54: 277-289.

Celesia GG, Wanamaker WM (1972) "Psychiatric Disturbances in Parkinson's Disease", Diseases of the Nervous System 33: 577-583.

Clark AW, Lehmann J (1983) "Dementia with Widespread Lewy Bodies: Studies of the Neocortical Cholinergic System', Abstract, Canadian Association of Neuropathologists, 23rd Annual Meeting, September 29 - October 1, 1983, Banff, Alberta.

Folstein MF, Folstein SE, McHugh PR (1975) "Mini-Mental State, A Practical Method for Grading the Cognitive State of Patients for the Clinician", Journal of Psycholinguistic Research 12: 189-198.

Garron DC, Klawans HL, Narin F (1972) "Intellectual Functioning of Persons with Idiopathic Parkinsonism". Journal of Nervous and Mental Diseases 154: 445-452.

Goldman JE, Yen S-H, Chiu F-C, Peress NS (1983) " Lewy Bodies of Parkinson's Disease Contain Neurofilament Antigens", Science 221: 1082-1084.

Hakim AM, Mathieson G (1978) "Basis of Dementia in Parkinson's Disease", Lancet 2: 729.

Hakim AM, Mathieson G (1979) "Dementia in Parkinson Disease: A Neuropathologic Study", Neurology 29: 1209-1214.

Javoy-Agid F, Taquet H, Ploska A, Cherif-Zahar C, Ruberg M, Agid Y (1981) "Distribution of catecholamines in the ventral mesencephalon of human brain with special reference to Parkinson's disease", Journal of Neurochemistry 36: 2101-2105.
Kessler II (1978) "Parkinson's Disease in Epidemiologic Perspective", in: 'Advances in Neurology, Volume 19-Neurological Epidemiology: Principles and Clinical Applications', edited by B.S. Schoenberg, Raven Press, New York, Pgs. 355-384.

Lees AJ, Smith E (1983) "Cognitive Deficits in the Early Stages of Parkinson's Disease", Brain 106: 257-270.

Mann DMA, Yates PO (1983) "Pathological Basis for Neurotransmitter Changes in Parkinson's Disease", Neuropathology and Applied Neurobiology 9: 3-19.

Martin WE, Loewenson RB, Resch, JA, Baker AB (1973) "Parkinson's Disease: Clinical Analysis of 100 Patients"', Neurology 23: 783-790.

Marttila RJ, Rinne UK (1976) "Dementia in Parkinson's Disease", Acta Neurologica Scandinavica 54: 431-441.

Mayeux R, Stern Y, Rosen J, Benson F (1981) "Subcortical Dementia: A Recognizable Clinical Entity", Transactions of the American Neurological Association 106: 313-316.

Mayeux R, Stern Y (1983) "Intellectual Dysfunction and Dementia in Parkinson Disease", in: 'The Dementias', edited by R. Mayeux and W.G. Rosen, Raven Press, New York, Pgs. 211-227.

Moss V (1982) "Intellectual Deterioration Associated with Parkinson's Disease in the Elderly", Proceedings of 9th Annual Meeting, Ontario Psychogeriatric Association, Pages 313-316.

Mortimer JA, Pirozzolo FJ, Hansch E, Webster DD (1982) "Relationship of Motor Symptoms to Intellectual Deficits in Parkinson's Disease", Neurology 32: 133-137.

Nakano I, Hirano A (1983) "Neuron Loss in the Nucleus Basalis of Meynert in Parkinsonism-Dementia Complex of Guam ", Annals of Neurology 13: 87-91.

Parkinson J (1938) "An Essay on the Shaking Palsy, 1817", Medical Classics 2: 964-997.

Perry RH, Candy JM, Perry EK, Irving D, Blessed G, Fairbairn AF, Tomlinson BE (1983a) "Extensive Loss of Choline Acetyltransferase is Not Reflected by Neuronal Loss in the Nucleus of Meynert in Alzheimer's Disease", Neuroscience Letters 33: 311-315.

Perry RH, Tomlinson, BE, Candy JM, Blessed G, Foster JF, Bloxham CA, Perry EK (1983b) "Cortical Cholinergic Deficit in Mentally Impaired Parkinsonian Patients"', Lancet 2: 789-790.

Pirozzolo FJ, Hansch EC, Mortimer JA, Webster DD, Kuskowski MA (1982) "Dementia in Parkinson Disease: A Neurophysiological Analysis", Brain Cognition 1: 71-83.

Ruberg M, Ploska A, Javoy-Agid F, Agid Y (1982) "Muscarinic Binding and Choline Acetyltransferase Activity in Parkinsonian Subjects with Reference to Dementia", Brain Research 232: 129-139.

Selby G (1968) "Cerebral Atrophy in Parkinsonism", Journal of the Neurological Sciences 6: 517-559.

Sroka H, Elizan TS, Yahr MD, Burger A, Medazu MR (1981) " Organic Mental Syndrome and Confusional States in Parkinson's Disease", Archives of Neurology 38: 339-342.

Whitehouse PJ, Struble RG, Clark AW, Price DL (1982a) "Alzheimer Disease: Plaques, Tangles and the Basal Forebrain", Annals of Neurology 12: 494.

Whitehouse PJ, Price DL, Struble RG, Clark AW, Coyle JT, DeLong MR (1982b) "Alzheimer's Disease and Senile Dementia: Loss of Neurons in the Basal Forebrain", Science 215: 1237-1239.

Whitehouse PJ, Hedreen JC, White CL, Price DL (1983) "Basal Forebrain Neurons in the Dementia of Parkinson's Disease", Annals of Neurology 13: 243-248.

Wilcock GK, Esiri MM (1982) "Plaques, Tangles and Dementia: A Quantitative Study", Journal of the Neurological Sciences 56: 343-356.

Wilcock, GK, Esiri MM, Bowen DM, Smith CCT (1982) "Alzheimer's Disease: Correlation of Cortical Choline Acet yltransferase Activity with the Severity of Dementia and Histological Abnormalities". Journal of the Neurological Sciences 56: 407-417.

Wilcock GK, Esiri MM, Bowen DM, Smith CCT (1983) "The Nucleus Basalis in Alzheimer's Disease: Cell Counts and Cortical Biochemistry", Neuropathology and Applied Neurobiology 9: 175-179.

Williams J (Editor) (1980) "Diagnostic and Statistical Manual of Mental Disorders", 3rd edition, American Psychiatric Association, Washington, D.C. 